\title{
Psychological Implications of COVID-19 Pandemic - A Wide Spectrum of Manifestations
}

\author{
Smrithi Chhabra ${ }^{1}$ \\ ${ }^{1}$ Department of Psychiatry, CMCH, Bhopal, Madhya Pradesh, India.
}

\section{ABSTRACT}

\section{BACKGROUND}

The COVID-19 pandemic has swept across the globe causing high morbidity and mortality and has brought in its wake, not only social and economic problems but also a myriad of psychological problems which if not addressed properly may not be as dangerous as the pandemic itself, but will contribute considerably to a significant loss of productivity in the society. Physical health and mental health, both are equally important and interdependent. "A sound mind in a sound body" is the need of the hour; but the present scenario is far from this. Unfortunately, with people suffering from physical illnesses as well as devastating mental sequelae of the pandemic, has resulted in social, financial, economic, and emotional impact. It is very important to identify and treat the mental health problem faced by the general population, quarantine people, health care professionals, at-risk-groups, and the victims of COVID-19 pandemic. Mental health problems can be in the form of depressive disorders, various anxiety disorders, stress related disorders, suicide and intentional self-harm, grief reaction, substance abuse (alcohol, tobacco, cannabis, opioids) and domestic violence. We have only limited resources available to us during these difficult times. However, this should not dissuade us from ensuring optimal mental health and from trying to keep the struggling humanity "sane" during this pandemic. These resources must be used judiciously and appropriately, with necessary modifications (telephonic / audio-video consultations and counselling) in order to prepare a society which can move forward in the post pandemic era.

\section{KEYWORDS}

Global, Pandemic, COVID-19, Quarantine, Psychological Problems, Mental Health, Victims, Optimal Use, Modification, Sane, Counselling
Corresponding Author: Dr. Smrithi Chhabra,

Chirayu Medical College and Hospital, Bairagarh, Bhopal, Madhya Pradesh, India. E-mail: smrithicaj@gmail.com

DOI: $10.14260 /$ jemds/2020/517

How to Cite This Article:

Chhabra S. Psychological implications of COVID-19 pandemic - a wide spectrum of manifestations. J Evolution Med Dent Sci 2020;9(33):2386-2391, DOI: $10.14260 /$ jemds/2020/517

Submission 22-04-2020,

Peer Review 06-07-2020,

Acceptance 13-07-2020,

Published 17-08-2020.

Copyright (C) 2020 JEMDS. This is an open access article distributed under Creative Commons Attribution License [Attribution 4.0 International (CC BY 4.0)] 


\section{BACKGROUND}

Originating from a small cluster of pneumonia or severe LRTI cases in Wuhan province of China, the COVID-19 or SARS-COV2 has escalated and snowballed into a widespread pandemic with a myriad of psychological implications. Worldwide the number of cases has sky-rocketed to 5,397,669 cases and resulted in death of 343,923 people. Around 2,247,345 people have recovered from the dreaded disease so far.[1,2] In India alone although the start has been low and the "go" has been "slow", yet it has increased to $1,25,000$ with a mortality of 3,867 cases. ${ }^{[1,2]}$ Around 54,441 COVID-19 +ve cases have been cured, yet 51,401 cases are active in the country.[1,2] These figures are still high, taking into account the limited COVID-19 testing kits and asymptomatic or pre-symptomatic or mildly symptomatic cases and some degree of under-reporting. Our reporting system may not be perfect and due to the overburdened administration, there is bound to be some degree of lapse as far as reporting is concerned.[1,2]

Not only COVID-19 pandemic, but any pandemic for that matter with ramifications of such vast proportions and such distressing, social, financial, psychological and emotional consequences is bound to have a long lasting effect on the mental health of the people.[1,2] The impact on mental health may differ from culture to culture and from country to country and across continents, but some commonalities or a common denominator with regard to mental health implications.[1,2] This article attempts to focus on the general mental health implications of this widespread pandemic.[1,2] The mental health impact may either be due to the direct effect of the pandemic (e.g. high rates of morbidity and mortality) or due to the secondary effects of the pandemic - social, financial, family, emotional consequences.[1,2] Both will be discussed in this article. Also, the myriad of mental health issues may be different in a particular subset of population (example, doctors, nurses, health care workers), then on a different subset of population (migrant labourers, daily-wages workers and skilled workers like plumber, electricians, car mechanics).[1,2] Add to the above, the issue of domestic violence which may have increased globally due to close proximity and physical confinement within the house due to the lockdown.[1,2] Domestic violence has its own mental health implications. [1,2] "Fear of the unknown" has often been used as a popular saying. ${ }^{[3,4]}$ In the context of COVID-19 pandemic, let us modify this popular saying as "Fear of the lesser known", with its share of unpredictability and uncertainty as to what would happen, who will survive and who will not, the livelihood / jobs of people and business entrepreneurs, etc. ${ }^{[3,4]}$

\section{DEPRESSION}

Depressive disorder can arise in the background of this pandemic among health care workers and health care seekers alike. ${ }^{[4,5]}$ The fear of contracting the disease, fear of isolation and quarantine, fear of being away from families and fear of having to die alone are large contributing factors to depression. $.4,5]$ If somebody has survived the disease whereas a loved one has died from the disease, "survival guilt" may play a big role in contributing to depression. ${ }^{[4,5]}$ For many victim who have contracted the disease and are in the late stages, depression may arise from the family members being unable to visit, denial of proper last rites, denial of authorities to hand over the body.[4,5] Depression among the healthcare workers (doctors, nurses, emergency staff, isolation ward staff) may arise due to being overburdened with work, inadequate or lack of availability of PPE kits and N-95 mask, inadequate protection, fear of contracting the disease while discharging one's duties, long working hours and "Burn Out Syndrome". [5] In many countries, doctors and nurses are on isolation duty for 14 days followed by a quarantine period ranging from 7 days to 14 days. Many doctors and nurses may avoid going home in order to safeguard their loved ones, which may lead to feeling of despair and depression. [5]

\section{ANXIETY AND STRESS}

The COVID-19 pandemic can lead to cognitive, emotional, somatic, autonomic and behavioural symptoms of anxiety which may be present in varying degrees among the general population at risk.[6] Cognitive symptoms can manifest as poor concentration, memory problem, a feeling of helplessness, a feeling of long control.[6] Emotional symptom can manifest as fear, apprehension a feeling of dread or impending doom, anger outbursts and irritability.[6] Somatic symptoms can manifest as insomnia, aches and pains, loss of appetite, loss of libido.[6] Autonomic symptoms can be in the form of palpitations, chambers, urinary urgency and gastro-intestinal irritability. Behavioural symptoms of anxiety can manifest as aggressive behaviour, violent behaviour, avoidance of people and places and situations.[6] These symptoms may amount to specific disorders like panic disorder or phobias.[6,7]

The author thinks it imperative to mention "health anxiety" in relation to COVID-19 pandemic.[6,7] Although health anxiety can be present up to varying degrees even among the general population, it can become highly exaggerated during the COVID-19 pandemic. Misinterpretation or catastrophization, maximization or normal body sensations or slightly altered body sensations can occur.[6,7] A heightened perception of slightly uncomfortable or slightly noxious bodily sensation can occur. Even the areas of brain's processing of sensory information can get altered leading to a sense of heightened perception to pain or other unpleasant sensations.[6,7] Add to this, the media hype of cases, presentation of inaccurate information, over-dramatic or theatrical presentation of cases (contrasting with a matter - of - fact - presentation): the health anxiety can be greatly increased by these factors. ${ }^{[6,7]}$ This can manifest as excessive apprehension or fear, seeking unnecessary or unwarranted health consultations or total avoidance of consultation, hoarding medication like Hydroxychloroquine or ivermectin, hoarding masks, etc.[6,7] It can even lead to selective targeting of particular communities or ethnic groups, a general lack of trust in the authorities or health sector. All of these are bound to have disastrous implications as the mutual trust between the communities, the health care sector and the public authorities will be lost.[6,7] Acute stress reaction can occur among the family member of a loved one who has died from the pandemic.[6,7] Even post-traumatic stress disorder can occur in family members or doctors and nurses who have witnessed a lot of suffering and rather catastrophic deaths of victims of COVID-19 pandemic.[6,7] 


\section{SUICIDE AND INTENTIONAL SELF HARM}

When the author talks of suicide in COVID-19 pandemic, this has to be discussed in relation to general suicide and attempted/completed suicides among COVID-19 patients. Again there are bound to be cross-cultural and cross-country variations in suicide rate with Japan, paradoxically mentioning reduced suicide rates during the lockdown. ${ }^{[8]}$ This is because of the emergence of "protective" factors such as more time available with family, lessening of stress, less of performance anxiety and less commuting to and from the workplace. ${ }^{[8]}$ However, in most of the countries including India, suicide rates may increase. Globally, experts have warned that the impact of COVID-19 on economy, business enterprises and joblessness can erode the self-esteem of people and can thus drive them towards suicide.[9] Social isolation, building frustration, unpredictable and uncertain future, fear of poverty and homelessness, coupled with the well-known risk factors (depression, substance abuse) can escalate suicide like never before. ${ }^{[9]}$ However, behind these individual factors lies the inability of the mass society to deal with this alarming situation. ${ }^{[9]}$

Fear of contracting the COVID-19 illness, fear of quarantine / self-isolation, lack of specific medications/ vaccines and the very high case fatality of the disease are additional factor that contribute towards increase rate of suicides in this pandemic.[9] The first suicide case in India was reported on $12^{\text {th }}$ February, 2020, wherein a man mistook his normal viral URTI to be COVID-19 infection and first isolated himself and then committed suicide. ${ }^{[9,10]}$ Whatever the outcome of the pandemic may be, unfortunately it has succeeded in creating negative thoughts and hopelessness about the self, the world and the future. ${ }^{[9,10]}$ What about suicides among the health care professionals? The health care professionals are at high risk of attempting and completing suicide due to various factors like fear of getting infection, unbearable stress, long and gruelling working hours and the psychological distress of having to watch COVID-19 patients die alone.[9,10,11] Add to this, the social discrimination and even violence faced by the health care professionals at the hands of the very society which they serve. No doubt they are driven to such desperate measures.[9,10,11] What about the patients who are diagnosed with COVID-19? Why do they commit suicide?[11] The fear of passing on the disease to their loved one, the knowledge that there is no "sure cure" other than supportive care, social stigma and discrimination attached to the disease, fear of dying alone, away from family are all contributing factors, not to exclude mis-information about the disease and dramatic media hype.[11]

\section{GRIEF}

It can result from death of a loved one. It can also result from surviving alone or the "I alone survived" phenomenon wherein the individual is the only survivor whereas all other victims have died.[12] The individual patient may even undergo what is called as "Anticipatory Grief" wherein he contracts the disease, knows that his chances of survival are slim in view of his medical comorbidities or a rather malignant course of the disease.[12,13]

\section{SOMATOFORM DISORDERS}

People may manifest with "unexplained physical symptoms" which have no organic disease and physical findings/ examination as well as the lab result may not show any evidence of physical disease.[14] Such patient may even become "hypochondriac" - they may insist that they have a particular disease affliction affecting a particular organ/system and may insist on getting themselves investigated for that particular disease.[14] Such type of patients may overburden an already fragile and over-worked health care system.[14] This can lead to frustration among health care seekers and health care providers and a lack of mutual trust and respect.[14]

\section{SUBSTANCE ABUSE}

The issue of substance abuse during COVID-19 pandemic deserves a specific mention in this article. People who are already actively using substances and are substance dependent may not have accessibility to and availability of the substance and this may lead to severe craving, physical and psychological withdrawal symptoms, trying to deploy desperate means to gain access to the substance, leading to an increase in the number of thefts, robbery, shop-lifting and other petty crimes.[15] This will further tax the police and other security forces who are already burdened with maintaining law and order and making people obey the rules/regulation/norms during the lockdown.[15] Such people may behave irresponsibly and may act as potential vectors of virus transmission.[15] They may have limited access to treatment adherence and detoxification centers during the pandemic and hence their morbidity and mortality may increase. ${ }^{[15]}$ They may already stretch their fragile finances to the utmost limit to procure the substance (alcohol, cannabis, tobacco), which may leave a little financial reserve for emergency. ${ }^{[15,16]}$ Regular alcohol and tobacco use can facilitate and aggravate the COVID-19 illness by compromising the immune system.[15,16] An overdose of opioids can prove fatal or potentially fatal in a patient with mild COVID-19 illness by causing respiratory depression. Similarly, smoking can exacerbate COPD and further compromise lung function in a patient with mild to moderate COVID-19 disease. WHO has already issued a warning about alcohol use during the pandemic.[15,16] To complicate matter further, alcohol abuse or other illicit drug abuse can increase the propensity/risks for domestic violence and physical and sexual abuse.[15,16]

\section{DOMESTIC VIOLENCE AND PHYSICAL / PSYCHOLOGICAL ABUSE}

Perhaps the biggest brunt of COVID-19 pandemic has been an upsurge in the cases of domestic violence. Consider this scenario, "Imagine a man already having a propensity for violence in a closed confinement with his spouse with nothing 
to keep him occupied, with his work/business going down and frustration building up. How does he react? He, in all probability, may react by showing or exhibiting violence towards his spouse, children or even parents." In the above described scenario, a slight provocation or even a casual remark or request for participation in household chores can become a precipitating factor for perpetrating domestic violence.[16,17] The police which was readily available earlier, may be busy elsewhere and hence the fear of which used to act as a deterrent earlier, may not work now.[16,17] With everyone under the lockdown, even social help (in the form of neighbours or NGOs) may not be available readily to the women.[16,17] This can increase the risk of depression, intentional self-harm and erode the woman's self-esteem so much that she may be driven to attempt suicide.[16,17]

\section{INTERVENTIONS}

Where do we go from here? How do we tackle this menace of not only the COVID-19 pandemic but also of the en masse psychological / mental health issues associated with this pandemic.[18] The first step to solving any problem is to identify and delineate the goals. Here the goals should be to minimize or mitigate the psychological distress associated with the pandemic and some sort of psychological rehabilitation post pandemic (when the dust finally settles).[18] The target population upon which we should focus includes

1. the general population.

2. the frontline workers - health care professionals, police, security personnel etc.

3. the at-Risk population - may include patients who have contracted COVID-19 illness and have survived/ are fighting against infection, elderly or young adults harbouring psychiatric comorbidities and children, the disabled/physically handicapped and those living in poverty.[18,19]

\section{Types of Intervention}

1. Pharmacotherapy/Drugs - Pharmacotherapy should be encouraged to be continued in all patients who have already been on medication for pre-existing psychiatric disorders. If availability of medications and cost even issue, long acting preparations with a once - a - day schedule can be used to substitute the previous medications.[18,19] For example, fluoxetine is longer acting and can be taken once a day, then, escitalopram and is also cheaper. Pharmacotherapy in combination with other modalities of treatment is by far the first choice in patients harbouring severe psychiatric disorders.

2. Education - The mental health professionals education of the general public about the psychological impacts of any pandemic is most important.[19] The emphasis should be on the fact that a psychological reaction to a crises as large as this one is expected and is 'okay' to have.[19] The public must be motivated to adopt strategies for disease prevention and health promotions. The general population should be encouraged to take all precautions and follow the norms / rules of the lockdown for their own safety as well as for safety of others.[19] It should be emphasized that even though there is a partial or a complete lockdown, there are still ways of connecting with each other (telephonically, through skype, video calls etc.).[19] The people should be encouraged to tap into their existing strengths and helped to "fit into their new roles".

3. Supportive Psychotherapy - Supportive psychotherapy (online) can be offered in an individual or a group setting for a particular subset of a population, for example, the healthcare professionals. It is generally aimed at symptom relief and behavioural modification (to minimize maladaptive behaviour like absenteeism) and to enhance productivity. ${ }^{[19,20]}$ Supportive psychotherapy, if diligently used, can help in improving the workers selfesteem, ego functioning and adaptive skills, which in turn would translate into work productivity.[19,20] It can be carried out once a week in small groups of $7-10$ individuals. $[19,20]$

4. Crisis Intervention - This is a specific type of intervention which can prove to be very useful in COVID19 pandemic. ${ }^{[19,20]}$ In the background of this pandemic, a crises can be defined by 3 factors - negative events (a loved one or the client himself contracting the COVID-19 infection), feeling of hopelessness associated with this negative event (the feeling that he/she may not make it, may die alone) and unpredictable events (sudden deterioration in physical condition of his own / a loved one's).[19,20,21] Such people who experience crises are overwhelmed by feelings of helplessness, powerlessness and a lack of control.[19,20,21] Crises intervention can be done online, but it must be done within 24 hours of a negative event, best is to do within the first 6 hours for it to be effective.

This intervention is best done individually or in family settings, either online or face to face, while maintaining appropriate social distancing. ${ }^{[20,21]}$ clients who are likely to benefit from crisis intervention are-

1. Doctors when one of them contracts this disease.

2. Nurses who have lost a colleague to the pandemic.

3. Quarantined individuals.

4. Family member whose loved one has contracted the COVID-19 and has not survived/is unlikely to survive. [20,21]

5. The aim should be to tap into the clients problem solving abilities and to restore him to his previous level of functioning.

5. Cognitive Behavioural Therapy - This therapy focuses on the correction of negative automatic thoughts and cognitive distortions and then the correction of underlying dysfunctional cognitive schemas.[20,21] The first two aspects are easier to correct than the one mentioned at the last. This type of therapy requires some degree of psychological sophistication and some degree of intelligence on part of the client. In the COVID-19 
pandemic, observable behaviours like bulk purchasing, hoarding of medications, excessive cleaning may underlie negative automatic thoughts like if I am not cleaning enough, I am doing enough, I am losing control, if I do not over prepare I may be the next victim, etc. Accompanied by these negative automatic thoughts are the cognitive distortions like maximization, minimization and catastrophization, etc.[20,21] It should be emphasized into the clients mind that what they value or is important to them, they are empowered to pursue that.[20,21] Acting according to their values will help them improve their self-efficacy and help them feel better about themselves and give them some sense of control over their lives although they cannot fully control the virus or what happens to them.[20,21]

6. Other Therapies - Other therapies like REBT, Eclectic Therapy, Brief Dynamic Psychotherapy, all play a role in this COVID-19 pandemic.[21]

Some general points to remember are

1. Most of us have already been taken down to the survival level of Maslow's hierarchy of needs. Earlier our motto was "Not only to survive but also to thrive". Now it is "Survive through this". Once the pandemic is over then if we have actually managed to survive, we can think about "thriving". [21,22] But we must remember that our priorities and the "new normal" in the post pandemic era will be different from the "old normal".[21,22]

\section{Doing Something Hard is Tough, Doing Nothing is Harder / Tougher}

For the younger generation which is a restless one, sitting at home quietly and doing nothing appears to be a big waste of both time as well as their "potential abilities".[21,22] Although most of the upper middle class and upper class older generation people may be content to sit at home spending quality time together with a well-stocked fridge full of eatables, the same cannot be said about the younger generation, the people of which very impatient, want to achieve everything in a short time and want immediate sense gratifications.[22] So, the youngsters may want to cultivate a new hobby or a past time and should be encouraged to do so.[22] Sketching, painting, developing a habit of reading, writing, cooking are some of the productive leisure activities which they can resort to during the COVID-19 pandemic.[22]

\section{Changing the Profession / Taking Up a New Profession Temporarily}

This may be an option available only to a selected few. But still it is worthwhile mentioning it in this article. The author's own friend, a community medicine professor has change his profession. He has now started business (both wholesale and retail) of supplying masks, face-shields, PPE to medical student and resident doctors. The idea is to do a business or resort to a livelihood which will hold our economy stable during the COVID-19 crisis.[23] Stitching facemasks (of cotton) which can be washed and re-used is another option. This should not be done impulsively or carelessly, rather it should be a wellthought of and a planned endeavour to tide over the crisis.

\section{Telephonic / Audio-Video Online Availability of Mental Health Services}

The various intervention and psychotherapies described earlier in this article may have to be done online rather than face to face. The problem is that many patients may not feel comfortable with the audio-video counselling. Children and adolescents may be more resistant since it deprives them the opportunity to connect with their therapist in Real-Time and hence they may perceive it as an assault on their autonomy, since it hampers their ability to seek therapy outside of home. ${ }^{[24]}$ Hence they may not respond well..[24] Adults and the elderly, who are stable and have had a long term therapy with their therapist / psychiatrist may not be so resistant and may do well with the Audio-Video Format.[24]

\section{Availability 24-Hours Helplines for Domestic Violence and Suicide Victims}

24 hours helplines should be made available for victims of domestic violence and for suicide victims and even for substance users.[25,26] It must be noted that the services of rehabilitation centres may not be available now.[25,26] The organization like Alcohol Anonymous are doing a commendable job by offering some respite to the people.[25,26] NGOs need to step in aggressively.

\section{Be Grateful and Thankful for What You Have}

While we sit and wait it out we must be thankful and grateful for what we have.[27] Spending quality time with loved ones, getting opportunity to explore our hidden potentials, reading, meditation, being kind to one another, conversation with family members and friends are some of the activities which may keep us "same" during the COVID-19 pandemic.[27] Observing nature as it blooms and taking comfort and even deriving joys from it can reduce stress levels.

\section{CONCLUSIONS}

The world is in the middle of a deadly pandemic. People should keep all their mental faculties intact and need gather their wits about them if they are to survive this pandemic. Isolation, home quarantine, and social distancing are important and must be emphasized, it is equally (if not more) important to combat or tackle the invisible psychological trauma resulting from this pandemic. Treating only the physical symptoms while ignoring the psychological implications will lead to an unproductive or a relatively less productive society postpandemic with long term devastating sequelae. Perhaps it is time to launch a specific website to address psychological and psychosocial issues.

Financial or Other Competing Interests: None. 


\section{REFERENCES}

[1] Montemurro N. The emotional impact of COVID-19: from medical staff to common people. Brain Behav Immun 2020;87:23-4.

[2] COVID-19 corona virus pandemic. Graphs-countries death rate-symptoms-transmission-worldometer info Last Updated 24 May 2020.

[3] Asmundson GJG, Taylor S. Coronaphobia: fear and the 2019-nCoV outbreak. J Anxiety Disord 2020;70:102196.

[4] Hoof EV. Lockdown is the world's biggest psychological experiment and we will pay the price. World Economic Forum Apr 9, 2020.

[5] Kang L, Li Y, Hu S, et al. The mental health of medical workers in Wuhan, China, dealing with the 2019 novel coronavirus. Lancet Psychiatry 2020;7(3):e14.

[6] Shigemura J, Ursano RJ, Morgamstein JC, et al. Public responses to the novel 2019 coronavirus (2019-nCoV) in Japan: mental health consequences and target populations. Psychiatry Clin Neurosci 2020;74(4):281-2.

[7] Shanafelt T, Ripp J, Trockel M. Understanding and addressing sources of anxiety among health care professionals during COVID-19 pandemic. JAMA Apr 7, 2020. DOI: $10.1001 /$ jama.2020.5893.

[8] Tanno S. Japan's suicide rate falls by a fifth during coronavirus pandemic. dailymail.co.uk May 14, 2020.

[9] Gunnell D, Appleby L, Arensman E, et al. Suicide risk and prevention during COVID-19 pandemic. Lancet Psychiatry 2020;7(6):468-71.

[10] Goyal K, Chauhan P, Chhikara K, et al. Fear of COVID-19: first suicidal case in India. Asian Journal of Psychiatry 2020;49:101989.

[11] Cheung YT, Chau PH, Yip PSF. A revisit on older adult suicides and severe acute respiratory syndrome [SARS] epidemic in Hong Kong. Int J Geriatric Psychiatry 2008;23(12):1231-8.

[12] Weir K. Grief and COVID-19: mourning our bygone lives. American Psychological Association Apr 1, 2020.

[13] Wallace CL, Wladkowski SP, White P. Grief during COVID19 pandemic: consideration for palliative care providers. J Pain Symptom Manage 2020;60(1):e70-6.
[14] Colizzi M, Bortoletto R, Zoccante L, et al. Medically unexplained symptoms in times of COVID-19 pandemic: a case report. Brain Behav Immun Health 2020;5:100073.

[15] Hein I. Alcohol abuse agitated by COVID-19 stirring liver concerns. Medicape May 06, 2020.

[16] Catala-Minana A, Lila M, Oliver A, et al. Contextual factors related to alcohol abuse among intimate partner violence offender. Subst Use Misuse 2017;52(3):294-302.

[17] Campbell AM. An increasing risk of family violence during the COVID-19 pandemic: strengthening community collaboration to save lives. Forensic Science International: Reports 2020;2:100089.

[18] Ho CS, Chee CI, Ho RC. Mental health strategies to combat the psychological impact of COVID-19 beyond paranoia and panic. Ann Acad Med Singapore 2020;49(3):156-60.

[19] Duan L, Zhu G. Psychological interventions for people affected by COVID-19 epidemic. Lancet Psychiatry 2020:7(4):300-2.

[20] Mental health and psychosocial consideration during the COVID-19 outbreak. World Health Organization March 18, 2020.

[21] Mental health in the times of COVID-19 pandemic. Guidance for general medical and specialized mental health care setting. National Institute of Mental Health and Neuroscience Apr 2020.

[22] Wang C, Pan R, Wan X, et al. Immediate psychological responses and associated factors during the initial stage of COVID-19 epidemic among the general population in China. Int J Environ Res Public Health 2020;17(5):1729.

[23] Tsai J, Wilson M. COVID-19: a potential public health problem for homeless populations. Lancet Public Health 2020;5(4):e186-7.

[24] Liu S, Yang L, Zhang C, et al. Online mental health services in China during COVID-19 outbreak. Lancet Psychiatry 2020;7(4):e17-8.

[25] Zhou X, Snoswell CL, Harding LE, et al. The role of telehealth in reducing mental health burden from COVID19. Telemed J E Health 2020;26(4):377-9.

[26] Xiao C. A novel approach of consultation on COVID-19 related psychological and mental problems: structured letter therapy. Psychiatry Investig 2020;17(2)175-6.

[27] Goldstein M. Benefits of gratitude during COVID-19. Psychiatric Times April 21, 2020. 